\title{
Interactions between Traumatic Brain Injury and Frontotemporal Degeneration
}

\author{
Mariel B. Deutsch ${ }^{a, c}$ Mario F. Mendez ${ }^{a-c}$ Edmond Teng ${ }^{a, c}$ \\ Departments of a Neurology and ${ }^{b}$ Psychiatry and Biobehavioral Sciences, David Geffen \\ School of Medicine, University of California, and ' Veterans Affairs Greater Los Angeles \\ Healthcare System, Los Angeles, Calif., USA
}

\section{Key Words}

Brain injuries - Frontotemporal degeneration - Frontotemporal dementia - Frontotemporal lobar degeneration · Primary progressive aphasia - Neuropsychological features in subjects with dementia

\begin{abstract}
Background/Aims: Prior work in smaller cohorts suggests that traumatic brain injury (TBI) may be a risk factor for frontotemporal degeneration (FTD). We sought to confirm and extend these results using the National Alzheimer's Coordinating Center Uniform Data Set. Methods: We compared the TBI prevalence between FTD subjects and matched normal controls. Indices of cognitive, behavioral, functional, and global dementia severity were compared between FTD subjects with and without prior TBI. Results: Remote TBI with extended loss of consciousness (TBI-ext) was more common in individuals with FTD than in controls (OR: 1.67; 95\% CI: 1.004-2.778). With TBI-ext, less functional and global impairment was seen in the behavioral variant of FTD, but more behavioral pathology was seen in the semantic variant. Conclusion: TBI may increase the FTD risk and influence clinical symptomatology and severity in FTD subtypes.

(C) 2014 S. Karger AG, Basel
\end{abstract}

\section{Introduction}

Frontotemporal degeneration (FTD) is one of the leading causes of neurodegenerative dementia in people under 60 years old [1]. It encompasses clinical diagnoses with symptoms attributable to progressive frontal and temporal lobe atrophy, including behavioral-variant 
Deutsch et al.: Interactions between Traumatic Brain Injury and Frontotemporal Degeneration

frontotemporal dementia (bvFTD) as well as nonfluent/agrammatic-variant and semanticvariant primary progressive aphasia [2, 3]. At autopsy, clinical diagnoses of FTD most often correlate with frontotemporal lobar degeneration (FTLD) neuropathology, including abnormal deposition of hyperphosphorylated tau, TDP-43, or FUS proteins in intraneuronal inclusion bodies [1].

Prior epidemiological studies have suggested that environmental factors, particularly traumatic brain injury (TBI), are associated with an increased prevalence of multiple neurodegenerative diseases including chronic traumatic encephalopathy (CTE) [4, 5], Alzheimer's disease (AD) [6-8], Parkinson's disease [9, 10], and amyotrophic lateral sclerosis [11, 12]. While up to $50 \%$ of FTD cases are familial, involving genetic mutations in chromosome 9 open reading frame 72, progranulin (PGRN), microtubule-associated protein tau, valosin-containing protein, or chromatin-modifying protein 2B [13], two studies have reported that TBI increases the risk for subsequent FTD $[14,15]$. However, TBI was not uniformly defined. Rosso et al. [14] operationalized TBI as head trauma followed by severe headache, nausea, blurred or double vision, vertigo, or amnesia, which occurred in 19 of 80 FTD subjects (24\%) versus only 10 of 124 normal controls (8\%), yielding an odds ratio (OR) of 3.3. Notably, only 5 FTD subjects had TBI with loss of consciousness (LOC). Kalkonde et al. [15] defined TBI as head trauma associated with alteration in consciousness, which occurred in 8 of 63 FTD subjects (13\%) versus 17 of 491 subjects with non-FTD dementias (3\%), yielding an OR of 4.4. The interpretation of these studies is limited by their relatively small sample sizes and broader definitions of TBI that did not incorporate the duration of LOC, the timing of head trauma relative to symptom onset, or potential confounders such as persistent neurologic deficits emerging as an immediate consequence of TBI. Nevertheless, the reported associations between TBI and subsequent FTD suggest that TBI may precipitate the deposition of FTLDassociated neuropathology such as hyperphosphorylated tau and/or TDP-43. However, clinicopathological studies to date have only substantiated the association between TBI and these proteinopathies in CTE $[4,16]$ and severe head injury [17].

In this study, we used the National Alzheimer's Coordinating Center (NACC) Uniform Data Set (UDS), a large multicenter database that includes detailed clinical, cognitive, behavioral, and functional assessments, to further investigate the association between TBI and FTD. In particular, our analyses focused on the relationship between FTD and TBI severity and the effects of TBI on clinical phenotype in FTD.

\section{Methods}

The NACC UDS includes data from research participants evaluated at National Institute of Aging (NIA)funded Alzheimer Disease Centers (ADCs) throughout the USA. Full details of the UDS have previously been reported [18] and can be found at www.alz.washington.edu. Written informed consent, approved by the institutional review board of each ADC, was obtained from each participant and/or their authorized representative.

We identified NACC UDS participants with clinical diagnoses of bvFTD, nonfluent/agrammatic-variant primary progressive aphasia [designated progressive nonfluent aphasia (PNFA) in the UDS], and semanticvariant primary progressive aphasia [designated semantic dementia (SD) in the UDS] at their baseline visit. Although the corticobasal syndrome and progressive supranuclear palsy are also considered to be part of the FTD spectrum [19], UDS participants with these diagnoses were not included in our analyses as we chose to focus on individuals with cognitive or behavioral symptoms as the primary manifestation of their underlying neurodegenerative conditions. bvFTD was diagnosed using the criteria of Neary et al. [20]. PNFA and SD were diagnosed using Mesulam's criteria [2, 3]. We also identified UDS participants with normal cognition (NC) at their baseline visit; they were matched 2:1 with participants with FTD for sex, age ( \pm 2 years), and education ( \pm 2 years). 
Fig. 1. Subsets of participants evaluated for different levels of TBI severity. Numbers in parentheses represent potential subjects at risk for different categories of TBI. Subjects with unknown TBI status were excluded from the total number of participants $(\mathrm{n}=3,031)$.

\begin{tabular}{l|l}
\hline \multicolumn{2}{l}{ Dement Geriatr Cogn Disord 2015;39:143-153 } \\
\hline DOI: 10.1159/000369787 & $\begin{array}{l}\text { @ 2014 S. Karger AG, Basel } \\
\text { www.karger.com/dem }\end{array}$ \\
\hline
\end{tabular}

Deutsch et al.: Interactions between Traumatic Brain Injury and Frontotemporal Degeneration

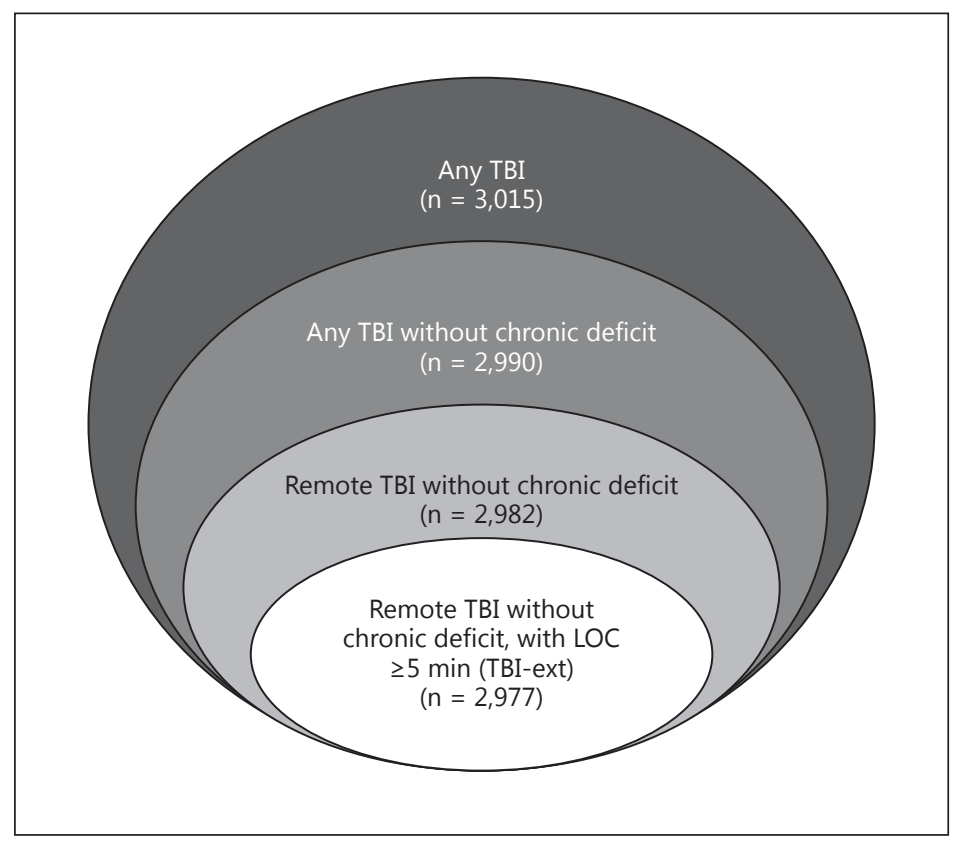

The UDS assesses for 3 levels of TBI severity, characterized by: (1) brief LOC ( $<5 \mathrm{~min}$ ), (2) extended LOC ( $\geq 5 \mathrm{~min}$ ), and (3) chronic deficit/dysfunction. The time course of each TBI is coded as: (1) recent/active (within 1 year of assessment or requiring active management), (2) remote/inactive (>1 year prior to assessment, not requiring active treatment), or (3) unknown. In order to assess the association between the time and severity of TBI and a clinical diagnosis of FTD, we compared the prevalence of TBI in the FTD and NC groups using increasingly stringent criteria (fig. 1): (1) any TBI, (2) any TBI without chronic neurologic deficit, (3) remote TBI without chronic neurologic deficit, and (4) remote TBI without chronic neurologic deficit but with extended LOC $\geq 5$ min (TBI-ext). We were primarily interested in the last category (TBI-ext), which represents a remote head injury of sufficient severity to result in extended LOC but not neurologic deficits. As such, the TBI-ext group would be expected to be most sensitive to detecting deficits related to the interaction between TBI and subsequent neurodegenerative disease, by excluding acute and chronic deficits directly attributable to the TBI itself and milder TBIs that are less likely to precipitate neurodegenerative changes [8].

Within the clinical subtypes of FTD (bvFTD, PNFA, and SD), we performed further analyses comparing cognitive, behavioral, functional, and global indices between participants with and without prior TBI-ext. Cognition was assessed with the Mini-Mental State Examination (MMSE) [21], logical memory IA and IIA of the revised Wechsler Memory Scale (WMS-R) [22], forward and reverse digit span from the WMS-R [22], Trail Making Test parts A and B [23], digit symbol from the revised Wechsler Adult Intelligence Scale (WAIS-R) [24], verbal fluency for animals and vegetables [25], and the odd-numbered items of the Boston Naming Test [26]. Raw scores for these assessments were converted to Z scores adjusted for age, sex, and education using the NACC UDS normative calculator [27]. Behavioral symptoms were assessed with the summed severity score of the Neuropsychiatric Inventory-Questionnaire (NPI-Q) [28]. Functional status was assessed using two separate global indices calculated from the Functional Activities Questionnaire (FAQ) [29]: (a) total FAQ scores, which only include data from participants with valid responses to all items, and (b) average FAQ item scores, which include data from all participants; this approach has previously been described [30-32]. Global dementia severity was assessed with the Clinical Dementia Rating (CDR) sum of boxes [33].

Statistical analyses were performed using SPSS 22 for Windows (IBM, Armonk, N.Y., USA). Demographic variables were compared between the FTD and NC groups using $\chi^{2}$ tests for nominal variables (sex, race, and FTD subtype) and unpaired t tests for continuous variables (age and years of education). The unadjusted prevalence rates of TBI in the FTD and NC groups were initially compared using $\chi^{2}$ tests and then subsequently analyzed with conditional multivariable logistic regression analyses to adjust for demographic differences. Demographic variables, the age at onset of cognitive/behavioral symptoms, the interval between 
Dementia

Cognitive Disorders

Table 1. Demographic data for participants with FTD or NC

\begin{tabular}{l|l}
\hline \multicolumn{2}{|l}{ Dement Geriatr Cogn Disord 2015;39:143-153 } \\
\hline DOI: $10.1159 / 000369787$ & $\begin{array}{l}\text { C 2014 S. Karger AG, Basel } \\
\text { www.karger.com/dem }\end{array}$ \\
\hline
\end{tabular}

Deutsch et al.: Interactions between Traumatic Brain Injury and Frontotemporal Degeneration

\begin{tabular}{lccr}
\hline & FTD participants & NC participants & \multicolumn{1}{c}{$\mathrm{p}$} \\
\hline Total number & 1,016 & 2,015 & \\
Male, \% & 59.6 & 59.4 & 0.878 \\
Age, years & $64.32(9.54)$ & $65.25(9.81)$ & $<0.014$ \\
Education, years & $15.14(3.13)$ & $15.66(3.02)$ & $<0.001$ \\
White, \% & 95.1 & 83.4 & $<0.001$ \\
\hline
\end{tabular}

Values denote means (standard deviations) unless specified otherwise. $p$ values in italics are significant.

Table 2. Prevalence of TBI in FTD versus NC

\begin{tabular}{lllll}
\hline Any TBI & $\begin{array}{l}\text { Any TBI without } \\
\text { chronic neurologic } \\
\text { deficit }\end{array}$ & $\begin{array}{l}\text { Remote TBI without } \\
\text { chronic neurologic } \\
\text { deficit }\end{array}$ & $\begin{array}{l}\text { Remote TBI without } \\
\text { chronic neurologic deficit } \\
\text { with LOC } \geq 5 \text { min (TBI-ext) }\end{array}$ \\
\hline FTD, \% & 12.9 & 12.3 & 11.0 & 4.3 \\
$\mathrm{NC}, \%$ & 11.5 & 10.9 & 10.0 & 2.9 \\
$\mathrm{n}^{\mathrm{a}}$ & 3,015 & 2,990 & 2,982 & 2,977 \\
$\mathrm{p}$ & 0.250 & 0.279 & 0.421 & 0.035 \\
\hline $\mathrm{OR}$ & 1.131 & 1.141 & 1.062 & 1.670 \\
$95 \%$ CI & $0.850-1.506$ & $0.851-1.531$ & $0.781-1.445$ & $1.004-2.778$ \\
$\mathrm{n}^{\mathrm{a}}$ & 2,951 & 2,927 & 2,919 & 2,914 \\
$\mathrm{p}$ & 0.397 & 0.378 & 0.702 & 0.048 \\
\hline
\end{tabular}

Top: unadjusted prevalences of TBI in FTD. Bottom: OR of FTD after TBI, adjusted for age, race, and years of education. $p$ values in italics are significant.

a The number of subjects varied due to missing demographic data (from total $n=3,031$ ).

symptom onset and UDS evaluation (i.e. symptom duration), as well as cognitive, behavioral, functional, and global dementia severity indices were compared across the FTD subtypes using one-way analyses of variance. Within each FTD subtype, cognitive, behavioral, functional, and global dementia severity indices were compared between participants with and without prior TBI-ext using unpaired t tests. Additionally, given the recently heightened public awareness of the relationship between TBI and neurodegenerative disease, we also used unpaired t tests to investigate whether FTD patients with prior TBI-ext either reported cognitive/ behavioral symptoms at earlier ages or underwent ADC evaluation at earlier stages of disease progression than those without prior TBI-ext. Subjects with missing data for individual comparisons were excluded from those particular analyses.

\section{Results}

Demographics

We identified 1,016 FTD subjects (710 with bvFTD, 154 with PNFA, and 152 with SD) and 2,015 matched NC participants whose baseline data were entered into the NACC UDS between September 2005 and May 2013. The demographic data for the two groups are shown in table 1. Due to the relatively young age of the FTD subjects, there were not enough agematched NC participants to complete the 2:1 match. Despite our matching protocol, the FTD participants remained significantly younger $[\mathrm{t}(3,029)=2.463, \mathrm{p}=0.014]$ and less well educated $[\mathrm{t}(2,986)=4.336, \mathrm{p}<0.001]$ than the $\mathrm{NC}$ participants. 
Deutsch et al.: Interactions between Traumatic Brain Injury and Frontotemporal Degeneration

Table 3. Demographic data for participants with FTD with and without prior TBI-ext

\begin{tabular}{lccccc}
\hline & With TBI-ext & $\mathrm{n}^{\mathrm{a}}$ & Without TBI-ext & $\mathrm{n}^{\mathrm{a}}$ & $\mathrm{p}$ \\
\hline Male, \% & 69.8 & 43 & 58.8 & 947 & 0.153 \\
Age, years & $63.23(11.31)$ & 43 & $64.37(9.46)$ & 947 & 0.444 \\
Age at symptom onset, years & $59.21(11.71)$ & 42 & $59.34(9.38)$ & 940 & 0.933 \\
Symptom duration, years & $4.07(2.15)$ & 42 & $5.00(3.83)$ & 940 & 0.119 \\
Education, years & $15.17(2.56)$ & 42 & $15.13(3.16)$ & 932 & 0.979 \\
White, \% & 95.3 & 43 & 95.0 & 936 & 0.913 \\
\hline
\end{tabular}

Values denote means (standard deviations) unless specified otherwise. Patients with recent TBI or TBI

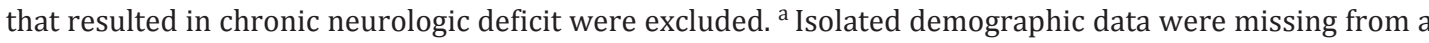
small proportion of participants (total $n=990$ ).

\section{Traumatic Brain Injury}

The prevalence of different categories of TBI in the FTD and NC groups is shown in table 2. Univariable analyses indicated that only TBI-ext was significantly more common in the FTD group than in the NC group $\left[\chi^{2}(2,977)=4.43, p=0.035\right]$. This finding remained robust in a conditional multivariable logistic regression analysis that was adjusted for group differences in age, education, and race. The demographic variables were similar in FTD subjects with and without prior TBI-ext, including both age at symptom onset and symptom duration (table 3 ). Of the clinical FTD subtypes, TBI-ext was most frequently reported in SD (6.8 vs. $4.0 \%$ in PNFA and 3.9\% in bvFTD); however, this comparison was relatively underpowered and did not reach statistical significance $\left[\chi^{2}(2,990)=2.59, \mathrm{p}=0.274\right]$.

\section{TBI Effects on Demographic, Cognitive, Behavioral, Functional, and Global Dementia}

Severity Indices in Clinical FTD Subtypes

After exclusion of participants with recent/active TBI and chronic deficit/dysfunction, we found that demographic variables and scores on the neuropsychological testing battery (NPI-Q, FAQ, and CDR sum of boxes) were significantly different across the bvFTD $(n=694)$, PNFA ( $\mathrm{n}=150)$, and SD ( $\mathrm{n}=146)$ subtypes (online suppl. table; for all online suppl. material, see www.karger.com/doi/10.1159/000369787). Therefore, we performed separate analyses on each subtype to ascertain potential effects of TBI-ext on these variables (tables 4,5).

\section{Behavioral-Variant Frontotemporal Dementia}

Similar cognitive performance was seen in bvFTD participants with and without TBI-ext, with the exception of a significantly better performance on reverse digit span in those with prior TBI-ext $[\mathrm{t}(536)=-2.323, \mathrm{p}=0.021]$. Additionally, significantly lower global FAQ indices [FAQ total: $\mathrm{t}(502)=1.981, \mathrm{p}=0.048$; FAQ average: $\mathrm{t}(686)=2.073, \mathrm{p}=0.039$; indicative of better functional performance] and lower CDR sum of boxes scores $[t(692)=2.343, p=0.019$; indicative of lower overall dementia severity] were seen in the bvFTD subjects with prior TBI-ext. Scores on other cognitive measures and the NPI-Q were similar in bvFTD participants with and without prior TBI-ext.

\section{Progressive Nonfluent Aphasia}

Similar scores were seen on the cognitive, behavioral, functional, and global dementia severity assessments between PNFA participants with and without prior TBI-ext. 
Deutsch et al.: Interactions between Traumatic Brain Injury and Frontotemporal Degeneration

Table 4. Cognitive indices in clinical FTD subtypes, stratified by exposure to TBI-ext

\begin{tabular}{|c|c|c|c|c|c|c|c|c|c|c|}
\hline Cognition Z scores & & bvFTD & $\mathrm{n}^{\mathrm{a}}$ & $\mathrm{p}$ & PNFA & $\mathrm{n}^{\mathrm{a}}$ & $\mathrm{p}$ & SD & $\mathrm{n}^{\mathrm{a}}$ & $\mathrm{p}$ \\
\hline MMSE & $\begin{array}{l}-\mathrm{TBI} \\
+\mathrm{TBI}\end{array}$ & $\begin{array}{l}-6.491 \\
-4.435\end{array}$ & $\begin{array}{r}581 \\
25\end{array}$ & 0.113 & $\begin{array}{l}-6.989 \\
-5.518\end{array}$ & $\begin{array}{r}125 \\
5\end{array}$ & 0.640 & $\begin{array}{l}-8.804 \\
-8.352\end{array}$ & $\begin{array}{r}115 \\
10\end{array}$ & 0.901 \\
\hline Logical memory IA & $\begin{array}{l}-\mathrm{TBI} \\
+\mathrm{TBI}\end{array}$ & $\begin{array}{l}-1.818 \\
-1.524\end{array}$ & $\begin{array}{r}491 \\
23\end{array}$ & 0.289 & $\begin{array}{l}-1.866 \\
-1.752\end{array}$ & $\begin{array}{r}96 \\
4\end{array}$ & 0.859 & $\begin{array}{l}-2.626 \\
-2.702\end{array}$ & $\begin{array}{r}85 \\
6\end{array}$ & 0.845 \\
\hline Logical memory IIA & $\begin{array}{l}-\mathrm{TBI} \\
+\mathrm{TBI}\end{array}$ & $\begin{array}{l}-1.642 \\
-1.306\end{array}$ & $\begin{array}{r}487 \\
23\end{array}$ & 0.176 & $\begin{array}{l}-1.358 \\
-1.149\end{array}$ & $\begin{array}{r}91 \\
4\end{array}$ & 0.720 & $\begin{array}{l}-2.185 \\
-2.383\end{array}$ & $\begin{array}{r}83 \\
6\end{array}$ & 0.539 \\
\hline Forward digit span & $\begin{array}{l}-\mathrm{TBI} \\
+\mathrm{TBI}\end{array}$ & $\begin{array}{l}-1.200 \\
-0.790\end{array}$ & $\begin{array}{r}520 \\
23\end{array}$ & 0.182 & $\begin{array}{l}-2.280 \\
-2.292\end{array}$ & $\begin{array}{r}103 \\
5\end{array}$ & 0.988 & $\begin{array}{l}-1.443 \\
-1.551\end{array}$ & $\begin{array}{r}98 \\
9\end{array}$ & 0.869 \\
\hline Reverse digit span & $\begin{array}{l}-\mathrm{TBI} \\
+\mathrm{TBI}\end{array}$ & $\begin{array}{l}-1.362 \\
-0.709\end{array}$ & $\begin{array}{r}515 \\
23\end{array}$ & 0.021 & $\begin{array}{l}-1.689 \\
-2.278\end{array}$ & $\begin{array}{r}100 \\
4\end{array}$ & 0.368 & $\begin{array}{l}-0.999 \\
-1.377\end{array}$ & $\begin{array}{r}95 \\
9\end{array}$ & 0.434 \\
\hline $\begin{array}{l}\text { Category fluency - } \\
\text { animals }\end{array}$ & $\begin{array}{l}-\mathrm{TBI} \\
+\mathrm{TBI}\end{array}$ & $\begin{array}{l}-2.168 \\
-1.703 \\
\end{array}$ & $\begin{array}{r}515 \\
24 \\
\end{array}$ & 0.064 & $\begin{array}{l}-2.208 \\
-2.491 \\
\end{array}$ & $\begin{array}{r}106 \\
5 \\
\end{array}$ & 0.595 & $\begin{array}{l}-2.964 \\
-2.827 \\
\end{array}$ & $\begin{array}{r}103 \\
9 \\
\end{array}$ & 0.635 \\
\hline $\begin{array}{l}\text { Category fluency - } \\
\text { vegetables }\end{array}$ & $\begin{array}{l}-\mathrm{TBI} \\
+\mathrm{TBI}\end{array}$ & $\begin{array}{l}-1.598 \\
-1.390 \\
\end{array}$ & $\begin{array}{r}497 \\
23 \\
\end{array}$ & 0.398 & $\begin{array}{l}-1.260 \\
-1.456 \\
\end{array}$ & $\begin{array}{r}100 \\
5 \\
\end{array}$ & 0.724 & $\begin{array}{l}-2.151 \\
-2.106 \\
\end{array}$ & $\begin{array}{r}86 \\
6 \\
\end{array}$ & 0.929 \\
\hline Boston Naming Test & $\begin{array}{l}-\mathrm{TBI} \\
+\mathrm{TBI}\end{array}$ & $\begin{array}{l}-2.738 \\
-2.134 \\
\end{array}$ & $\begin{array}{r}503 \\
23\end{array}$ & 0.330 & $\begin{array}{l}-3.021 \\
-1.605\end{array}$ & $\begin{array}{r}101 \\
5\end{array}$ & 0.301 & $\begin{array}{l}-7.226 \\
-8.457 \\
\end{array}$ & $\begin{array}{r}92 \\
6 \\
\end{array}$ & 0.177 \\
\hline Trail Making Test part A & $\begin{array}{l}-\mathrm{TBI} \\
+\mathrm{TBI}\end{array}$ & $\begin{array}{l}-2.688 \\
-2.808\end{array}$ & $\begin{array}{r}458 \\
22\end{array}$ & 0.852 & $\begin{array}{l}-2.588 \\
-3.388\end{array}$ & $\begin{array}{r}100 \\
5\end{array}$ & 0.546 & $\begin{array}{l}-1.751 \\
-1.143\end{array}$ & $\begin{array}{r}91 \\
6\end{array}$ & 0.552 \\
\hline Trail Making Test part B & $\begin{array}{l}-\mathrm{TBI} \\
+\mathrm{TBI}\end{array}$ & $\begin{array}{l}-2.301 \\
-1.574\end{array}$ & $\begin{array}{r}347 \\
18\end{array}$ & 0.142 & $\begin{array}{l}-2.802 \\
-2.578\end{array}$ & $\begin{array}{r}86 \\
5\end{array}$ & 0.803 & $\begin{array}{l}-1.521 \\
-1.982\end{array}$ & $\begin{array}{r}79 \\
6\end{array}$ & 0.561 \\
\hline WAIS-R digit symbol & $\begin{array}{l}-\mathrm{TBI} \\
+\mathrm{TBI}\end{array}$ & $\begin{array}{l}-1.799 \\
-1.947\end{array}$ & $\begin{array}{r}441 \\
21\end{array}$ & 0.667 & $\begin{array}{l}-1.684 \\
-1.929\end{array}$ & $\begin{array}{r}99 \\
5\end{array}$ & 0.714 & $\begin{array}{l}-0.924 \\
-0.963\end{array}$ & $\begin{array}{r}86 \\
6\end{array}$ & 0.948 \\
\hline
\end{tabular}

Patients with recent TBI or TBI that resulted in chronic neurologic deficit were excluded. For cognitive Z scores, higher scores represent better performance. The p value in italics is significant. ${ }^{a}$ Isolated test data were missing from a small proportion of participants.

Table 5. Behavioral, functional, and global dementia severity indices in clinical FTD subtypes, stratified by exposure to TBI-ext

\begin{tabular}{|c|c|c|c|c|c|c|c|c|c|c|}
\hline & & bvFTD & $\mathrm{n}^{\mathrm{a}}$ & $\mathrm{p}$ & PNFA & $\mathrm{n}^{\mathrm{a}}$ & $\mathrm{p}$ & SD & $\mathrm{n}^{\mathrm{a}}$ & $\mathrm{p}$ \\
\hline \multicolumn{11}{|l|}{ Behavior } \\
\hline \multirow[t]{2}{*}{ NPI-Q score } & $-\mathrm{TBI}$ & 9.335 & 647 & 0.566 & 4.707 & 140 & 0.408 & 6.741 & 135 & 0.004 \\
\hline & $+\mathrm{TBI}$ & 10.000 & 27 & & 3.000 & 6 & & 11.667 & 9 & \\
\hline \multicolumn{11}{|l|}{ Function } \\
\hline \multirow[t]{2}{*}{ Total FAQ score } & $-\mathrm{TBI}$ & 21.050 & 484 & 0.048 & 12.990 & 97 & 0.426 & 15.529 & 102 & 0.657 \\
\hline & +TBI & 17.300 & 20 & & 8.800 & 5 & & 14.000 & 9 & \\
\hline \multirow[t]{2}{*}{ Average FAQ item score } & -TBI & 1.930 & 661 & 0.039 & 1.130 & 144 & 0.385 & 1.396 & 136 & 0.989 \\
\hline & $+\mathrm{TBI}$ & 1.574 & 27 & & 0.733 & 6 & & 1.400 & 9 & \\
\hline \multicolumn{11}{|l|}{ Global dementia severity } \\
\hline \multirow[t]{2}{*}{ CDR sum of boxes score } & $-\mathrm{TBI}$ & 7.933 & 667 & 0.019 & 4.538 & 144 & 0.487 & 5.596 & 136 & 0.581 \\
\hline & +TBI & 5.722 & 27 & & 3.083 & 6 & & 4.800 & 10 & \\
\hline
\end{tabular}

Patients with recent TBI or TBI that resulted in chronic neurologic deficit were excluded. Higher scores indicate greater impairment. $p$ values in italics are significant. ${ }^{a}$ Isolated assessment data were missing from a small proportion of participants. 


\section{Semantic Dementia}

Higher NPI-Q summed severity scores were seen in SD participants exposed to prior TBI-ext relative to those without prior TBI-ext $[\mathrm{t}(142)=-2.897, \mathrm{p}=0.004$; indicative of greater behavioral pathology]. This was primarily driven by higher severity scores for anxiety $[\mathrm{t}(142)=-4.189, \mathrm{p}<0.001]$ and elation $[\mathrm{t}(142)=-3.275, \mathrm{p}=0.001]$ in SD with prior TBI-ext. There were no differences between SD participants with and those without prior TBI-ext in any of the cognitive, functional, or global dementia severity assessments.

\section{Symptom Onset and Duration}

The age at symptom onset was similar between FTD subjects with ( $59.21 \pm 11.71$ years) and those without (59.34 \pm 9.38 years) prior TBI-ext $[\mathrm{t}(980)=0.084, \mathrm{p}=0.933$ ] (table 3 ) as well as for individual FTD subtypes with (bvFTD: $57.56 \pm 11.89$ years; PNFA: $66.80 \pm 11.08$; SD: $59.90 \pm 10.97$ ) and without (bvFTD: $58.48 \pm 9.61$ years; PNFA: $63.02 \pm 8.83$; SD: $59.75 \pm$ 7.77) prior TBI-ext [bvFTD: $\mathrm{t}(689)=0.485, \mathrm{p}=0.628$; PNFA: $\mathrm{t}(143)=-0.933, \mathrm{p}=0.352$; $\mathrm{SD}$ : $\mathrm{t}(144)=-0.057, \mathrm{p}=0.954]$. A similar symptom duration was also seen between FTD subjects with $(4.07 \pm 2.15$ years $)$ and without $(5.00 \pm 3.83$ years) prior TBI-ext $[\mathrm{t}(980)=1.560, \mathrm{p}=$ 0.119 ] (table 3 ) as well as for individual FTD subtypes with (bvFTD: $3.89 \pm 1.97$ years; PNFA: $3.20 \pm 0.84$; SD: $5.00 \pm 2.83$ ) and without (bvFTD: $5.17 \pm 4.18$ years; PNFA: $4.32 \pm 2.36$; SD: $4.88 \pm 3.10$ ) prior TBI-ext [bvFTD: $\mathrm{t}(689)=1.581, \mathrm{p}=0.114$; PNFA: $\mathrm{t}(143)=1.057, \mathrm{p}=0.292$; SD: $\mathrm{t}(144)=-0.124, \mathrm{p}=0.902]$.

\section{Discussion}

Our analyses of the NACC UDS indicate that TBI with extended LOC is a significant risk factor for a clinical diagnosis of FTD. These findings emerged after excluding data from participants with recent/active TBI or TBI resulting in chronic neurological deficits, suggesting that they are not simply a direct consequence of TBI-related brain dysfunction but potentially arise from the precipitation and/or acceleration of subsequent neurodegenerative disease. Our OR for TBI in FTD subjects relative to matched controls was 1.67, which is substantially lower than the 3.3-4.4 reported in previous studies $[14,15]$ which examined the association between FTD and any prior TBI, regardless of severity. This difference may be related to population-based variability. The FTD cohort of Kalkonde et al. [15] had a mean age of 71.3 years, which is considerably higher than the age of the cohort examined here (mean age: 64.3 years), and their control group had non-FTD dementias as opposed to NC. The FTD cohort of Rosso et al. [14] was similar in age to our FTD cohort, but their control group was less rigorously assessed for cognitive impairment. Our results indicate that only remote TBI with LOC $\geq 5$ min was associated with increased FTD risk, and they parallel prior work demonstrating that only moderate-to-severe TBI is associated with increased rates of AD [8].

A prior investigation using the NACC UDS suggested that only TBI with chronic deficit/ dysfunction (and not TBI limited to either brief or extended LOC) was associated with an increased risk for all-cause dementia [34]. Those analyses, which included the entire cohort of demented participants within the UDS, were heavily weighted with participants with dementia due to AD. Therefore, it is possible that the association between TBI and the much smaller cohort of FTD participants in the UDS may have been obscured in their analyses, particularly since FTD and NC subjects in our study were on average 5-8 years younger than the subjects in their study. Indeed, the role of TBI may be more pronounced in early-onset dementias, particularly since TBI may accelerate underlying neurodegenerative disease [35].

TBI may promote the development of FTD through its effects on microglial activation, which can lead to progranulin deficiency [36]. Progranulin appears to play a role in neuronal 
Deutsch et al.: Interactions between Traumatic Brain Injury and Frontotemporal Degeneration

growth and repair, and acquired progranulin deficiency could precipitate neurodegeneration, similar to the progranulin deficiency that arises from PGRN mutations associated with FTD [37]. Since the frontal and temporal lobes are particularly susceptible to damage in TBI, these regions may also be particularly susceptible to TBI-related progranulin depletion. Furthermore, TDP-43 deposition may be initiated by TBI, since it has been observed in cases of CTE [16], and it has been suggested that CTE may be a form of acquired FTLD [38]. Of the clinical FTD subtypes, TDP-43 pathology has been most strongly associated with SD [39-41], which, in our study, had the highest prevalence of TBI-ext.

We also found potential TBI-related differences in clinical features for two of the FTD subtypes. First, bvFTD participants with prior TBI-ext had significantly better functional performance and lower overall dementia severity relative to those without prior TBI-ext. The underlying explanation for these findings remains uncertain. One possibility is that patients with a history of significant TBI may be more attuned to cognitive or functional decline and present for formal evaluation at earlier disease stages than those without a history of TBI, resulting in better performance on these measures. Although bvFTD subjects with prior TBI-ext were younger at symptom onset and had shorter symptom durations prior to ADC assessments than those without prior TBI-ext, these differences were not statistically significant. Alternatively, bvFTD associated with environmental factors such as TBI may be characterized by different patterns of underlying neuropathology than bvFTD associated with genetic factors and thus exhibit a less aggressive course. Although our FAQ and CDR findings in bvFTD are buttressed by an apparent association between TBI-ext and better performance on reverse digit span, we did not see similar associations between TBI-ext and other tests of attention and executive function in the UDS (forward digit span, Trail Making Test parts A and $\mathrm{B}$, and WAIS-R digit symbol), which may limit the clinical significance of this result. Second, SD subjects with prior TBI-ext exhibited greater behavioral pathology as measured by the NPI-Q. This is particularly notable considering that, irrespective of TBI exposure, behavioral dysfunction is more common in SD than in other forms of primary progressive aphasia [42]. While the increased behavioral symptoms are likely attributable to the greater susceptibility of frontal and temporal regions to TBI-related damage and subsequent neurodegenerative changes, it remains unclear why this association is seen only in the SD group and not in the bvFTD and PNFA groups.

Our results are consistent with a previous analysis of participants with all-cause dementia in the NACC UDS that demonstrated that those with prior TBI with extended LOC or chronic deficit/dysfunction exhibited significantly better performance on a subset of cognitive assessments but had significantly more behavioral disturbances [43]. Although the largest proportion of participants in their sample met clinical criteria for probable AD, approximately $17 \%$ were diagnosed with either bvFTD or primary progressive aphasia. Based on their results, the authors postulated that TBI may result in distinctly different clinical phenotypes in dementia [43]. However, the question of whether these TBI-related phenotypic differences are reflected by different patterns of underlying neurodegenerative pathology remains unresolved and will need to be addressed with careful clinicopathological investigations in FTD patients with or without prior TBI.

There are a number of factors that may limit the interpretation of our results. First, the reporting of prior TBI in the NACC UDS is retrospective and therefore subject to recall bias. We attempted to limit this potential bias by focusing on more severe TBIs (i.e. associated with LOC $\geq 5 \mathrm{~min}$ ), which are presumably of similar significance to both NC and FTD participants (or their informants) [43]. Second, the coding of TBI severity in the UDS (LOC $<5 \mathrm{~min}$, LOC $\geq 5$ min, and with chronic deficit/dysfunction) does not precisely align with TBI severity ratings typically used in clinical practice (mild, moderate, and severe), which may limit the generalization of our findings. Third, the time of TBI relative to dementia onset is not captured in the 
Deutsch et al.: Interactions between Traumatic Brain Injury and Frontotemporal Degeneration

UDS but is important to consider because TBI that occurs after the onset of FTD symptoms (but prior to ADC evaluation) may be misclassified as a risk factor for FTD rather than a potential consequence of the disease. Although our study focused on remote TBI (i.e. >1 year prior to ADC evaluation), the mean interval between symptom onset and initial ADC evaluation was 4-5 years, which leaves a relatively small but still potentially confounding window for such misclassifications. Fourth, despite our matching protocol, FTD subjects were significantly younger and less well educated than the NC subjects. However, these differences were $<1$ year each and may not be clinically meaningful. Moreover, we adjusted for these differences in our statistical analyses. Fifth, although to our knowledge this is the largest study to date of TBI risk in FTD subjects, the subgroup analyses of the effects of TBI-ext within each FTD subtype, particularly PNFA and SD, incorporated much more limited sample sizes. Sixth, the NACC UDS was not specifically designed to capture FTD subjects, and much like the overall UDS study population, the FTD cohort analyzed here represents a convenience sample rather than a population-based sample. Therefore, our results may not be entirely generalizable to the larger FTD population. Nevertheless, we found a greater proportion of white subjects in our FTD group relative to our NC group, which is consistent with previous reports [44, 45]. Although the recently introduced NACC-FTLD module may be more sensitive to detecting deficits in FTD patients, the number of participants assessed with this tool remains more limited at this time. Seventh, the limited family history and genetic mutation data included in the UDS precluded a comprehensive analysis of the interaction between TBI and genetic risk factors in the FTD cohort. Finally, there currently are not enough FTD participants with data in both the NACC UDS and Neuropathology databases to determine whether similar proportions of those with and without prior TBI-ext exhibit FTLD pathology. Of the 43 FTD participants in the UDS with a history of TBI-ext, only 4 had corresponding data in the Neuropathology database; 3 had FTLD pathology and 1 had AD pathology. This is in agreement with prior reports that approximately $75-80 \%$ of the larger set of bvFTD participants included in both the NACC UDS and Neuropathology databases exhibit neuropathological findings consistent with FTLD $[46,47]$. However, the Neuropathology database does not currently ascertain CTE-associated pathology.

Our findings indicate that TBI associated with extended LOC may increase the subsequent risk for FTD by approximately $67 \%$ and differentially affects both the pattern and severity of cognitive, behavioral, and functional symptomatology across clinical FTD subtypes. Since there are currently no curative treatments for FTD, prevention becomes correspondingly more important. Although environmental factors are likely to be responsible for only a small proportion of FTD cases, minimizing putative risk factors such as TBI may be one potential approach. Although our analyses of the relationship between TBI and FTD include data from significantly more participants than earlier reports, they require confirmation by future population-based studies that incorporate clinicopathological correlations and more precisely explore the number and time course of TBIs needed to increase FTD risk. Such studies will advance our understanding of the mechanistic relationships between TBI and FTD, and facilitate the development of interventions that have the potential to ameliorate this association.

\section{Acknowledgments}

This study was supported by the NIA (P50 AG16570 and K08 AG34628 to E.T.; jointly sponsored by the NIA, the American Federation for Aging Research, the John A. Hartford Foundation, the Atlantic Philanthropies, the Starr Foundation, and an anonymous donor) and R01AG034499-05 (M.F.M., principle investigator), the Alzheimer's Disease Research Centers of California, and the Sidell-Kagan Foundation. The NACC database is funded by the NIA (U01 AG016976). 
Deutsch et al.: Interactions between Traumatic Brain Injury and Frontotemporal Degeneration

\section{References}

Perry DC, Miller BL: Frontotemporal dementia. Semin Neurol 2013;33:336-341.

Mesulam MM: Primary progressive aphasia. Ann Neurol 2001;49:425-432.

Mesulam MM: Primary progressive aphasia - a language-based dementia. N Engl J Med 2003;349:1535-1542. McKee AC, Cantu RC, Nowinski CJ, Hedley-Whyte ET, Gavett BE, Budson AE, Santini VE, Lee HS, Kubilus CA, Stern RA: Chronic traumatic encephalopathy in athletes: progressive tauopathy after repetitive head injury. J Neuropathol Exp Neurol 2009;68:709-735.

5 Jordan BD: Chronic traumatic brain injury associated with boxing. Semin Neurol 2000;20:179-185.

-6 Bazarian JJ, Cernak I, Noble-Haeusslein L, Potolicchio S, Temkin N: Long-term neurologic outcomes after traumatic brain injury. J Head Trauma Rehabil 2009;24:439-451.

7 Ishibe N, Wlordarczyk RC, Fulco C: Overview of the Institute of Medicine's Committee search strategy and review process for Gulf War and Health: long-term consequences of traumatic brain injury. J Head Trauma Rehabil 2009;24:424-429.

-8 Plassman BL, Havlik RJ, Steffens DC, Helms MJ, Newman TN, Drosdick D, Phillips C, Gau BA, Welsh-Bohmer KA, Burke JR, Guralnik JM, Breitner JC: Documented head injury in early adulthood and risk of Alzheimer's disease and other dementias. Neurology 2000;55:1158-1166.

-9 Goldman SM, Tanner CM, Oakes D, Bhudhikanok GS, Gupta A, Langston JW: Head injury and Parkinson's disease risk in twins. Ann Neurol 2006;60:65-72.

10 Bower JH, Maraganore DM, Peterson BJ, McDonnell SK, Ahlskog JE, Rocca WA: Head trauma preceding PD: a case-control study. Neurology 2003;60:1610-1615.

$\checkmark 11$ Chen H, Richard M, Sandler DP, Umbach DM, Kamel F: Head injury and amyotrophic lateral sclerosis. Am J Epidemiol 2007;166:810-816.

12 Strickland D, Smith SA, Dolliff G, Goldman L, Roelofs RI: Physical activity, trauma, and ALS: a case-control study. Acta Neurol Scand 1996;94:45-50.

13 Onyike CU, Diehl-Schmid J: The epidemiology of frontotemporal dementia. Int Rev Psychiatry 2013;25:130137.

14 Rosso SM, Landweer EJ, Houterman M, Donker Kaat L, van Duijn CM, van Swieten JC: Medical and environmental risk factors for sporadic frontotemporal dementia: a retrospective case-control study. J Neurol Neurosurg Psychiatry 2003;74:1574-1576.

15 Kalkonde YV, Jawaid A, Qureshi SU, Shirani P, Wheaton M, Pinto-Patarroyo GP, Schulz PE: Medical and environmental risk factors associated with frontotemporal dementia: a case-control study in a veteran population. Alzheimers Dement 2012;8:204-210.

16 McKee AC, Gavett BE, Stern RA, Nowinski CJ, Cantu RC, Kowall NW, Perl DP, Hedley-Whyte ET, Price B, Sullivan C, Morin P, Lee HS, Kubilus CA, Daneshvar DH, Wulff M, Budson AE: TDP-43 proteinopathy and motor neuron disease in chronic traumatic encephalopathy. J Neuropathol Exp Neurol 2010;69:918-929.

-17 Smith C, Graham DI, Murray LS, Nicoll JA: Tau immunohistochemistry in acute brain injury. Neuropathol Appl Neurobiol 2003;29:496-502.

18 Morris JC, Weintraub S, Chui HC, Cummings J, Decarli C, Ferris S, Foster NL, Galasko D, Graff-Radford N, Peskind ER, Beekly D, Ramos EM, Kukull WA: The Uniform Data Set (UDS): clinical and cognitive variables and descriptive data from Alzheimer Disease Centers. Alzheimer Dis Assoc Disord 2006;20:210-216.

19 Bahia V, Takada L, Deramecourt V: Neuropathology of frontotemporal lobar degeneration: a review. Dement Neuropsychol 2013;7:19-26.

20 Neary D, Snowden JS, Gustafson L, Passant U, Stuss D, Black S, Freedman M, Kertesz A, Robert PH, Albert M, Boone K, Miller BL, Cummings J, Benson DF: Frontotemporal lobar degeneration: a consensus on clinical diagnostic criteria. Neurology 1998;51:1546-1554.

-21 Folstein MF, Robins LN, Helzer JE: The Mini-Mental State Examination. Arch Gen Psychiatry 1983;40:812.

22 Wechsler D: Wechsler Memory Scale-Revised (WMS-R) Manual. San Antonio, Psychological Corporation, Harcourt Brace Jovanovich Inc, 1987.

23 Reitan R, Wolfson D: The Halstead-Reitan Neuropsychological Test Battery. Theory and Clinical Interpretation. Tucson, Neuropsychology Press, 1985.

24 Wechsler D: Wechsler Adult Intelligence Scale-Revised. Digit Symbol Subtest. San Antonio, Psychological Corporation, 1987.

25 Butters N, Granholm E, Salmon DP, Grant I, Wolfe J: Episodic and semantic memory: a comparison of amnesic and demented patients. J Clin Exp Neuropsychol 1987;9:479-497.

26 Kaplan E, Goodglass H, Weintraub S: The Boston Naming Test. Philadelphia, Lea and Febiger, 1983.

27 Shirk SD, Mitchell MB, Shaughnessy LW, Sherman JC, Locascio JJ, Weintraub S, Atri A: A web-based normative calculator for the Uniform Data Set (UDS) neuropsychological test battery. Alzheimers Res Ther 2011;3:32.

28 Kaufer DI, Cummings JL, Ketchel P, Smith V, MacMillan A, Shelley T, Lopez OL, DeKosky ST: Validation of the NPI-Q, a brief clinical form of the Neuropsychiatric Inventory. J Neuropsychiatry Clin Neurosci 2000;12:233239.

29 Pfeffer RI, Kurosaki TT, Harrah CH Jr, Chance JM, Filos S: Measurement of functional activities in older adults in the community. J Gerontol 1982;37:323-329.

30 Teng E, Becker BW, Woo E, Cummings JL, Lu PH: Subtle deficits in instrumental activities of daily living in subtypes of mild cognitive impairment. Dement Geriatr Cogn Disord 2010;30:189-197. 
Deutsch et al.: Interactions between Traumatic Brain Injury and Frontotemporal Degeneration

31 Teng E, Becker BW, Woo E, Knopman DS, Cummings JL, Lu PH: Utility of the Functional Activities Questionnaire for distinguishing mild cognitive impairment from very mild Alzheimer disease. Alzheimer Dis Assoc Disord 2010;24:348-353.

-32 Hsiao JJ, Lu PH, Grill JD, Teng E: Longitudinal declines in instrumental activities of daily living in stable and progressive mild cognitive impairment. Dement Geriatr Cogn Disord 2014;39:12-24.

33 Morris JC: The Clinical Dementia Rating (CDR): current version and scoring rules. Neurology 1993;43:24122414.

34 Sayed N, Culver C, Dams-O'Connor K, Hammond F, Diaz-Arrastia R: Clinical phenotype of dementia after traumatic brain injury. J Neurotrauma 2013;30:1117-1122.

35 Nemetz PN, Leibson C, Naessens JM, Beard M, Kokmen E, Annegers JF, Kurland LT: Traumatic brain injury and time to onset of Alzheimer's disease: a population-based study. Am J Epidemiol 1999;149:32-40.

-36 Jawaid A, Rademakers R, Kass JS, Kalkonde Y, Schulz PE: Traumatic brain injury may increase the risk for frontotemporal dementia through reduced progranulin. Neurodegener Dis 2009;6:219-220.

-37 Finch N, Baker M, Crook R, Swanson K, Kuntz K, Surtees R, Bisceglio G, Rovelet-Lecrux A, Boeve B, Petersen RC, Dickson DW, Younkin SG, Deramecourt V, Crook J, Graff-Radford NR, Rademakers R: Plasma progranulin levels predict progranulin mutation status in frontotemporal dementia patients and asymptomatic family members. Brain 2009;132:583-591.

-38 McKee AC, Daneshvar DH, Alvarez VE, Stein TD: The neuropathology of sport. Acta Neuropathol 2014;127: 29-51.

39 Davies RR, Hodges JR, Kril JJ, Patterson K, Halliday GM, Xuereb JH: The pathological basis of semantic dementia. Brain 2005;128:1984-1995.

-40 Grossman M, Wood EM, Moore P, Neumann M, Kwong L, Forman MS, Clark CM, McCluskey LF, Miller BL, Lee VM, Trojanowski JQ: TDP-43 pathologic lesions and clinical phenotype in frontotemporal lobar degeneration with ubiquitin-positive inclusions. Arch Neurol 2007;64:1449-1454.

41 Galimberti D, Scarpini E: Genetics of frontotemporal lobar degeneration. Front Neurol 2012;3:52.

-42 Rosen HJ, Allison SC, Ogar JM, Amici S, Rose K, Dronkers N, Miller BL, Gorno-Tempini ML: Behavioral features in semantic dementia vs other forms of progressive aphasias. Neurology 2006;67:1752-1756.

-43 Dams-O'Connor K, Spielman L, Hammond FM, Sayed N, Culver C, Diaz-Arrastia R: An exploration of clinical dementia phenotypes among individuals with and without traumatic brain injury. NeuroRehabilitation 2013; 32:199-209.

44 Hou CE, Yaffe K, Pérez-Stable EJ, Miller BL: Frequency of dementia etiologies in four ethnic groups. Dement Geriatr Cogn Disord 2006;22:42-47.

45 Pressman PS, Miller BL: Diagnosis and management of behavioral variant frontotemporal dementia. Biol Psychiatry 2014;75:574-581.

46 Mendez MF, Joshi A, Tassniyom K, Teng E, Shapira JS: Clinicopathologic differences among patients with behavioral variant frontotemporal dementia. Neurology 2013;80:561-568.

47 Leger GC, Banks SJ: Neuropsychiatric symptom profile differs based on pathology in patients with clinically diagnosed behavioral variant frontotemporal dementia. Dement Geriatr Cogn Disord 2014;37:104-112. 